\title{
Punishing Hubris: The Perils of Overestimating One's Status in a Group
}

\author{
Cameron Anderson \\ University of California-Berkeley \\ Daniel R. Ames \\ Columbia University
}

Samuel D. Gosling

University of Texas-Austin

Individuals engage in status self-enhancement when they form an overly positive perception of their status in a group. We argue that status self-enhancement incurs social costs and, therefore, most individuals perceive their status accurately. In contrast, theories of positive illusions suggest status self-enhancement is beneficial for the individual and that most individuals overestimate their status. We found supportive evidence for our bypotheses in a social relations analysis of laboratory groups, an experiment that manipulated status self-enhancement, and a study of real-world groups. Individuals who engaged in status self-enhancement were liked less by others and paid less for their work. Moreover, individuals tended to perceive their status highly accurately. Mediation analyses showed that status self-enhancers were socially punished because they were seen as disruptive to group processes.

Keywords: status; hierarchy; self-perception; self-enhancement; positive illusions

\footnotetext{
A ccording to functionalist theories of status (Blau, 1964; Frank, 1985; Thibaut \& Kelley, 1959), status hierarchies provide many benefits for face-to-face groups, including coordinating group action and limiting conflicts over dominance and decision making (Bernstein, 1981; de Waal, 1982; Eibl-Eibesfeldt, 1989). Status hierarchies delineate a clear order of influence among group members-high-status members are allowed to make decisions for the group, control group processes, and dominate discussions, whereas low-status members are expected to defer to others and speak less (e.g., Bales, Strodtbeck, Mills, \& Roseborough, 1951; Berger, Cohen, \& Zelditch, 1972).
}

Functionalist theories of status imply two somewhat controversial hypotheses. First, they imply that individuals who engage in status self-enhancement will be punished by their group. Individuals with overly positive self-perceptions of status are likely to behave in highstatus ways even if they actually have low status (Anderson \& Berdahl, 2002; Bugental \& Lewis, 1999). Their behavior would disrupt group functioning, creating conflict and hindering the group's performance (Horowitz et al., 2006). In turn, the group is likely to punish status self-enhancement using all mechanisms available-which are typically social exclusion and ostracism (e.g., Blau \& Scott, 1962; Homans, 1951; Ridgeway \& Berger, 1986).

Second, functionalist theories imply that group members will typically perceive their status accurately. Individuals have a strong need to belong and be accepted in social groups (Baumeister \& Leary, 1995; Maslow, 1968). Given the social costs of engaging in status self-enhancement, individuals should be motivated to form accurate perceptions of their status to maintain their social acceptance. ${ }^{1}$

These hypotheses are controversial because they challenge the predominant positive illusions perspective, which suggests that self-enhancement biases are adaptive for the individual and that most individuals have

Authors' Note: Correspondence concerning this article should be addressed to Cameron Anderson, University of California, Walter A. Haas School of Business, 545 Student Services Bldg \#1900, Berkeley, CA 94720-1900; e-mail: anderson@haas.berkeley.edu.

PSPB, Vol. 34 No. 1, January 2008 90-101

DOI: $10.1177 / 0146167207307489$

(C) 2008 by the Society for Personality and Social Psychology, Inc. 
overly positive self-perceptions (e.g., Taylor \& Brown, 1988; Taylor, Lerner, Sherman, Sage, \& McDowell, 2003). For example, Krebs and Denton (1997) argued that engaging in status self-enhancement provides social benefits, leading others to believe the individual's status claim and, accordingly, to grant the individual high status. And Barkow (1975) argued that status selfenhancement provides psychological benefits by boosting individuals' self-esteem.

Empirical work has so far provided support for the functionalist perspective. Notably, Anderson, Srivastava, Beer, Spataro, and Chatman (2006) found a consistent negative correlation between status self-enhancement and social acceptance; individuals who engaged in status selfenhancement were liked less by their fellow group members. Moreover, individuals typically viewed their status accurately and not in overly positive ways.

In this article we investigate several important unanswered questions. First, we further delineate the outcomes associated with status self-enhancement. Whereas past work has focused on social costs (e.g., diminished social acceptance), we consider instrumental outcomes such as the levels of resources awarded by the group and psychological correlates such as self-esteem and narcissism (Study 1). Second, we unpack the mechanisms underlying group reactions to status self-enhancers, including the role of a status self-enhancer's disruptiveness to group processes (Study 2). Third, we test more definitively whether status self-enhancement causes decreases in social acceptance using an experimental design (Study 2). Fourth, we extend the effects beyond the laboratory, seeking evidence for the costs of status self-enhancement in real-world contexts (Study 3). The evidence presented here thus extends our understanding of how, why, and where status self-enhancement incurs costs for the individual.

\section{STUDY 1: THE INSTRUMENTAL AND PSYCHOLOGICAL CORRELATES OF STATUS SELF-ENHANCEMENT}

Even if status self-enhancement incurs social costs, it might be adaptive in other ways, providing instrumental or psychological benefits. According to Krebs and Denton (1997), "The value we attach to ourselvesour level of confidence and self-esteem, our sense of deservingness-are important sources of information about our worth. . . . Positive illusions induce others to overvalue us" (p. 38). Therefore, status self-enhancers might be more highly valued by their group and in turn more highly compensated financially. However, functionalist theories of status imply that groups punish status self-enhancers using any means they can. When groups control each individual's monetary compensation, they should pay status self-enhancers less for their work. Therefore, we expected status self-enhancement would damage individuals' instrumental outcomes.

As noted above, Barkow (1975) argued that status self-enhancement is adaptive because it boosts selfesteem. But is status self-enhancement associated with higher self-esteem? If status self-enhancement leads to lower levels of social acceptance and poorer interpersonal relationships, it might be a marker of dysfunctional and maladaptive psychological processes, not a sign of psychological health and well-being. In this case, status selfenhancement might relate to lower levels of self-esteem rather than higher. Moreover, it is possible that status selfenhancement is associated with narcissism. Narcissism involves a grandiose sense of self and entitlement as well as a preoccupation with success and demands for admiration (Morf \& Rhodewalt, 2001); it has been linked with the tendency to self-enhance (Gosling, John, Craik, \& Robins, 1998; John \& Robins, 1994) and with poor interpersonal relationships, particularly in the long run (for a review, see Vazire \& Funder, 2006). In Study 1, we tested the psychological as well as instrumental correlates of status self-enhancement.

\section{Operationalizing Status Self-Enhancement Using a Social Relations Analysis}

In Study 1, we studied small groups in the laboratory and collected round-robin ratings of status and social acceptance, where each member of the group rated himself or herself and every other members' status and acceptance. This design allowed us to analyze the data using the Social Relations Model (SRM; Kenny, 1994; Kenny \& La Voie, 1984), and to use a self-enhancement index recently developed by Kwan, John, Kenny, Bond, and Robins (2004).

The SRM index of self-enhancement arose in response to the different ways in which self-enhancement has been operationalized in the literature: Some studies use a social comparison approach, in which an individual's self-perceptions are compared to that individual's perceptions of others. For example, if an individual believes himself or herself to be an above-average driver, this is considered evidence of self-enhancement. Other studies use a self-insight approach, in which an individual's self-perceptions are compared to peers' perceptions of the individual. For example, if an individual believes himself or herself to be more intelligent than others believe him or her to be, this is considered evidence of self-enhancement. The SRM index represents a conceptual and methodological breakthrough because it integrates both approaches, comparing self-perceptions to perceptions of others and peers' perceptions of the individual (Kwan et al., 2004). 
Using a round-robin design also introduces a methodological concern, however. Prior research has shown that self-enhancement biases can be reduced when individuals are asked to rate specific other group members at the same time they rate themselves (Savitsky, Van Boven, Epley, \& Wight, 2005). For example, if individuals are asked to rate each of their fellow group members' performances on a task in addition to rating their own performance, selfenhancement biases can be attenuated. Therefore, if we were to find that individuals do not engage in status self-enhancement, the result might be an artificial by-product of our round-robin design, not a genuine absence of self-enhancement.

To help alleviate this concern, we tested whether individuals would engage in self-enhancement along another dimension at the same time they were accurate (and not self-enhancing) when perceiving their status. Specifically, we tested the hypothesis that individuals would engage in self-enhancement when perceiving their acceptance in the group.

In contrast to status self-enhancement, self-enhancing one's acceptance should not be socially punished because it does not challenge the status order (Anderson et al., 2006). Status self-enhancement should lead to agentic behavior such as asserting, controlling, and dominating (e.g., Anderson \& Berdahl, 2002). As work on complementarity has shown, agentic behavior is intended to invoke submissive behavior in others (e.g., Bakan, 1966; Hogan, 1996; Horowitz et al., 2006; T. Leary, 1957; Wiggins, 1979). For status self-enhancers, this intention would be deemed by others as inappropriate and a challenge to the existing hierarchical order. However, acceptance self-enhancement should lead to communal behaviors such as sharing, disclosing, and cooperating. These behaviors are intended to invoke similar sharing or cooperating behavior in others (Horowitz et al., 2006). This intention would not be seen as a threat to the existing hierarchy and, as a result, individuals should be freer to engage in selfenhancement when perceiving their acceptance.

Previous work provides indirect support for the hypothesis that acceptance self-enhancement is more prevalent than status self-enhancement is. Specifically, researchers have distinguished egoistic biases, or selfenhancement along dimensions related to competence and intelligence, from moralistic biases, or self-enhancement along dimensions related to honesty or cooperativeness (Paulhus \& John, 1998). And studies of the Muhammed Ali effect have found self-enhancement to be more prevalent along moral than egoistic dimensions (Allison, Messick, \& Goethals, 1989; Van Lange \& Sedikides, 1998). Because status often correlates with egoistic dimensions (competence and intelligence contribute to individual status) and acceptance often correlates with moralistic dimensions (honesty and cooperativeness contribute to acceptance), this provides indirect evidence for our hypothesis.

\section{Method}

\section{Participants}

Participants were 164 undergraduate students $(36.7 \%$ men, $63.3 \%$ women) at a West Coast university who worked in one of 41 four-person groups. They were 20 years old on average $(S D=3.14), 43 \%$ were Asian or Asian American, 37\% were Caucasian, 16\% were Latin American, and 4\% were African American. Participants were assigned to experimental sessions through volunteer sign-ups; they received course credit for their participation.

\section{Pregroup Task: Measuring \\ Self-Esteem and Narcissism}

Prior to the laboratory session, participants completed measures of self-esteem and narcissism as part of a broader participant-screening packet. Participants completed Rosenberg's (1965) 10-item self-esteem scale; example items are "On the whole, I am satisfied with myself" and "I take a positive attitude toward myself." Items were rated on a scale from 1 (strongly disagree) to 5 (strongly agree). The average score was $4.06(S D=0.65)$. Coefficient alpha was .86. Participants also completed the 40-item Narcissism Personality Inventory (Raskin \& Terry, 1988). Items on this scale ask participants to choose which of two statements is truer of them; for example, one item asks them to choose between "The thought of ruling the world frightens the hell out of me" and "If I ruled the world it would be a much better place." Answers were scored either a 1 or a 2, with the answer that reflected a more narcissistic tendency being scored a 2 . The average score was $1.41(S D=0.18)$. Coefficient alpha was .85 .

\section{Group Task}

Each group worked on an adapted version of the "Lost on the Moon" problem (Robins \& Beer, 2001), in which groups are told their team has crash-landed on the moon and needs to get back to the mother ship 200 miles away. They are given a list of items (e.g., a box of matches, parachute silk, two pistols) and asked to use those items to successfully make the 200-mile trip. We wanted to keep the duration that participants worked together constant across all groups, so we modified the task to make it unsolvable, omitting some necessary items. All groups worked for their allotted 45 minutes.

\section{Postgroup Task: Status and Acceptance Ratings and Lottery Ticket Allocation}

Following the group task, participants privately rated themselves and their teammates on three status-related 
items: whether the person had influence over the group, participated in the task, and made valuable contributions to the group. Each item was rated on a scale from 1 (not at all descriptive) to 8 (extremely descriptive). We used the software program SOREMO (Kenny, 1995) to implement the SRM analyses of these round-robin status ratings. For each participant, SOREMO calculates a target score, which is essentially the average of all others' ratings of the individual. In addition, SOREMO removes group differences, making target scores statistically independent of group membership (see Kenny \& La Voie, 1984). The three target scores had an alpha of .93, indicating high internal consistency of the overall status measure. Furthermore, target scores of the overall status measure showed statistically significant amounts of relative variance $(M=40 \%)$, indicating group members agreed about one another's status.

Participants also rated each group member's social acceptance: how much they were liked by the other group members and how much they liked each of the other members on the same 1 to 8 scale. We operationalized social acceptance as the individual's target score on liking (i.e., their average peer rating). There were significant amounts of target variance for acceptance $(11 \%)$, indicating groups generally liked some individuals more than others. However, the target variance for acceptance was relatively low, which is consistent with prior work; although there does tend to be consensus in groups regarding who is more or less liked, who likes and accepts whom is often unique and idiosyncratic (see Kenny, 1994).

To measure monetary compensation, participants were told in the posttask questionnaire that there would be four experiment-wide lotteries, each for a prize of $\$ 100$ in cash. They were told that participants' "chances of winning the $\$ 100$ depend on how many tickets they are awarded today-for example, if you get 20 tickets, you'll be twice as likely to win than if you get 10 tickets. If we draw one of your tickets, you will receive $\$ 100$ before the end of the term. Think about how many lottery tickets the other people in today's exercise should receive and type your response (from 0 to 25)." To avoid participants' giving their teammates fewer tickets simply to increase their own chances of winning, they were also told there were four independent lotteries and that they were competing in a lottery involving only participants from other groups. The average number of lottery tickets participants allocated to each teammate was $22.17(S D=5.98)$.

\section{Results and Discussion}

\section{The Social Outcomes of Status Self-Enhancement}

Measuring self-enhancement is somewhat complicated. According to Kwan et al. (2004), if an individual has a high perception of his or her status, he or she may not be engaging in self-enhancement because he or she might actually have high (peer-rated) status. Moreover, he or she may not be engaging in self-enhancement if he or she rates everyone's status as high; he or she may simply view the world in general more positively. Therefore, based on Kwan et al.'s method, we predicted individuals' peer-rated acceptance with their selfperceived status while controlling for their peer-rated status and their ratings of others' status. This way, we measured whether individuals perceived themselves as high in status, above and beyond others' perceptions of them, and above and beyond their perceptions of others.

Furthermore, we used a regression technique because of the problems associated with discrepancy scores (Edwards, 1994). For example, subtracting peer-rated status from self-rated status can confound the effects of the two variables. (Using the discrepancy score method provided highly similar results; no significant results dropped below significance and no nonsignificant results became significant.)

As expected, individuals who engaged in status selfenhancement were less accepted by fellow group members. We predicted peer-rated acceptance with selfrated status, $\beta=-.20, t(163)=-1.61, p=.05$, while controlling for peer-rated status, $\beta=.32, t(163)=3.11$, $p<.01$, and individuals' ratings of others' status, $\beta=.10$, $t(163)=1.10, n s$. This negative effect of self-perceptions was not moderated by gender. Moreover, the zero-order correlation between self-rated status and peer-rated acceptance was $r(164)=.08, n s$, which suggests that status self-enhancement, not higher status self-perceptions per se, related to lower levels of social acceptance.

We also tested for a curvilinear effect. We predicted peer-rated social acceptance with peer-rated status, $\beta=$ $.32, t(163)=3.12, p<.01$; individuals' rating of others' status, $\beta=.10, t(163)=1.04$, ns; self-perceived status, $\beta=-.19, t(163)=-1.48, n s$; and the quadratic term, which is the square of the self-perceived status score, $\beta=.03, t(163)=0.40, n s$. The lack of significance of the quadratic term indicates individuals who underestimated their status were more accepted than accurate perceivers, who in turn were accepted more than self-enhancers. However, we hesitate to conclude that underestimating one's status increases acceptance based on this finding because of the statistical difficulty of testing nonlinear effects (McClelland \& Judd, 1993).

\section{The Instrumental Outcomes of Status Self-Enhancement}

As shown in Figure 1, status self-enhancers were also compensated less for their work. We predicted the lottery tickets individuals were assigned with self-rated 


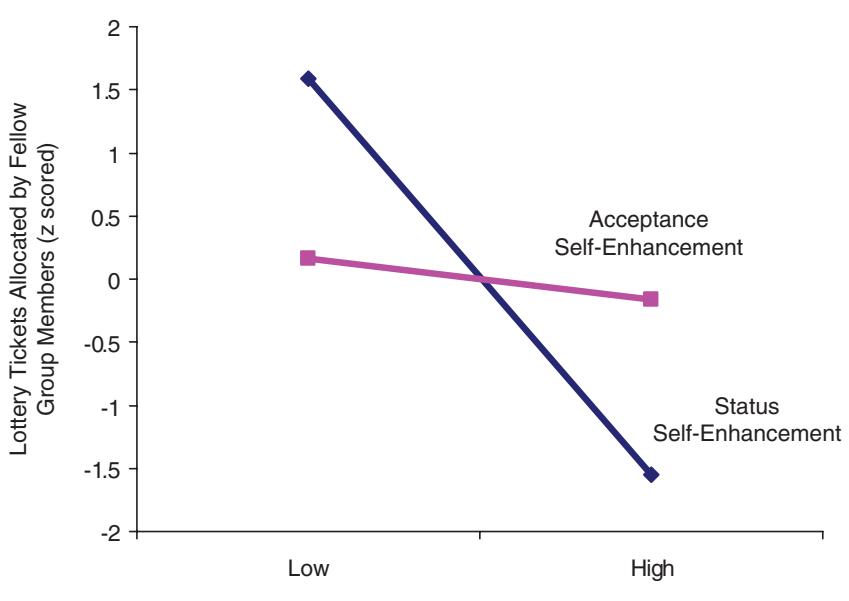

Figure 1 Study 1: Engaging in status self-enhancement led to receiving less material compensation from the group, whereas engaging in acceptance self-enhancement did not. "Low" and "high" refer to one standard deviation below and above the mean, respectively.

status, $\beta=-.32, t(163)=2.26, p<.05$; peer-rated status, $\beta=.19, t(163)=1.53, p=.12$; and individuals' ratings of others' status, $\beta=.11, t(163)=1.11$, ns. The zero-order correlation between self-rated status and the lottery tickets individuals were assigned was $r(164)=$ -.12 , ns, which again suggests that status self-enhancement, not higher status self-perceptions, related to a lower number of lottery tickets.

\section{The Psychological Outcomes of Status Self-Enhancement}

Self-esteem was unrelated to status self-enhancement. We predicted self-esteem with self-rated status, $\beta=.20$, $t(112)=1.51$, ns, while controlling for peer-rated status, $\beta=.11, t(112)=1.01, n s$, and individuals' ratings of others' status, $\beta=.15, t(112)=1.43$, ns. However, status self-enhancement was positively related to narcissism. We predicted narcissism with self-rated status, $\beta=.30, t(138)=2.38, p<.05$, while controlling for peer-rated status, $\beta=.06, t(138)=0.56$, ns, and individuals' ratings of others' status, $\beta=.02$, $t(112)=0.18, n s^{2}$

\section{Effects of Acceptance Self-Enhancement}

We could not examine the effects of acceptance selfenhancement on individuals' actual (peer-rated) acceptance because peer-rated acceptance would be included as a control variable and as the dependent variable. Therefore, we focused on the number of lottery tickets allocated by the group. As shown in Figure 1, acceptance self-enhancement did not predict a lower number of lottery tickets. We predicted the lottery tickets individuals were assigned with their self-rated acceptance, $\beta$ $=-.03, t(163)=-0.38, n s$, while controlling for peer-rated acceptance, $\beta=.07, t(163)=0.77, n s$, and individuals' ratings of others' acceptance, $\beta=-.05, t(163)=-0.48$, ns.

\section{Accuracy in Self-Perceptions of Status and of Acceptance}

Accuracy can mean many things both conceptually and operationally (Cronbach, 1955). One definition provided by Cronbach (1955) is differential accuracy, which in this context we defined as whether selfperceived status is positively correlated with peer-rated status. A second definition of accuracy is elevation accuracy, which is concerned with whether mean levels of self-perceptions are higher, lower, or about the same as others' perceptions (Cronbach, 1955). This is the sense of accuracy implied by the notion of self-enhancement versus self-effacement, or of overestimating versus underestimating one's own status. ${ }^{3}$

Differential accuracy. As expected, self-peer agreement was strong for status, $r=.67, p<.01$, indicating individuals were quite accurate in perceiving their status. However, there was not a significant correlation between individuals' self-perceived acceptance and how much they were actually accepted or liked by peers, $r=$ $.10, n s$, indicating individuals were not accurate when perceiving their acceptance. Using Raghunathan, Rosenthal, and Rubin's (1996) method, we found that individuals were significantly more accurate in perceiving their status than they were in perceiving their acceptance, $z=4.47, p<.01$.

Elevation accuracy. We ran a 3-way ANOVA at the group level with two within-subjects factors (self-perceptions vs. peer-perceptions and status vs. acceptance) and one between-subjects factor (the gender composition of the group). ${ }^{4}$ This analysis revealed a main effect for selfperception versus peer-perception, $F(1,36)=78.45, p<$ .01 , indicating a general self-enhancement effect across both perceptions of status and of acceptance.

Consistent with expectations, there was also a significant interaction, in that this self-enhancement effect was moderated by status versus acceptance perceptions, $F(1,36)=82.60, p<.01$. As shown in Table 1 , there was a significantly stronger self-enhancement effect in perceiving one's acceptance than in perceiving one's status. Planned comparisons showed that self-ratings of acceptance were significantly higher than peers' social acceptance ratings, $F(1,36)=115.38, p<.01$. In contrast, self-ratings of status were not significantly higher than peers' status ratings, $F(1,36)=3.67$, ns. Thus, 
TABLE 1: Study 1: Self-Ratings and Peer Ratings of Status and Social Acceptance

\begin{tabular}{lccc}
\hline & Self-Rated & Peer Rated & $\begin{array}{c}\text { Differential } \\
\text { Accuracy } \\
\text { (Self-Peer } \\
\text { Correlation) }\end{array}$ \\
\hline Status & $6.56(0.54)$ & $6.37(0.38)$ & $.67 *$ \\
Social acceptance & $5.75(0.69)$ & $4.39(0.53)$ & .10 \\
\hline
\end{tabular}

NOTE: Standard deviations are in parentheses. Self-perceptions of social acceptance are significantly higher than peer perceptions social acceptance. Self-perceptions of status are not higher than peer perceptions of status.

"p $<.01$.

people showed a self-enhancement bias in perceiving their acceptance and at the same time did not show such a bias in perceiving their status. There were no effects for the groups' gender composition.

\section{Summary}

Individuals who engaged in status self-enhancement were liked less by fellow group members, which is consistent with prior research (Anderson et al., 2006). Moreover, status self-enhancement was related to receiving less financial compensation from teammates; this suggests that status self-enhancement does not lead groups to overvalue the individual but instead to punish that individual monetarily. Status self-enhancers did not have higher levels of self-esteem but were higher in narcissism, suggesting that status self-enhancement does not provide psychological benefits; instead, it is related to what many consider an unhealthy personality dimension (see Vazire \& Funder, 2006). We also saw that acceptance self-enhancement did not harm individuals' financial compensation. Individuals were highly accurate in perceiving their status and did not engage in status self-enhancement, yet individuals were not accurate in perceiving their acceptance and did engage in acceptance self-enhancement.

\section{STUDY 2: AN EXPERIMENTAL ANALYSIS OF THE EFFECTS OF STATUS SELF- ENHANCEMENT AND ITS MEDIATORS}

We had three aims in Study 2. First, we wanted to examine causal evidence for the effects of status selfenhancement on social acceptance by using an experimental design. All the evidence for the effects of status self-enhancement on social acceptance has thus far been derived from correlational designs. It is, therefore, possible that decreased social acceptance has been causing status self-enhancement rather than vice versa; for example, individuals who were less accepted by their group might have tried to convince themselves that they had higher status to protect their self-esteem.

Second, we wanted to examine empirically the mediating mechanisms for the effects of status self-enhancement on social acceptance. We have argued that status self-enhancers incur social punishment because they disrupt the group's processes and effectiveness. By showing that status self-enhancement manifests itself in disruptiveness, we hope to help scholars and practitioners better anticipate the consequences of status self-enhancement and better diagnose the antecedents (such as status selfenhancement) of dysfunctional teamwork.

Third, in Study 1 we found a linear relationship between status self-enhancement and social acceptance, which implies individuals who underestimated their status were more accepted and liked than were individuals who accurately perceived their status. However, without a strong theoretical basis to hypothesize that status self-effacers are liked more than are accurate status perceivers and given the difficulty of obtaining statistically significant nonlinear effects (McClelland \& Judd, 1993), the absence of quadratic effects might have been because of a lack of statistical power. We examined this issue further by comparing the effects of status self-effacement to accurate status perceptions in our experimental design.

\section{Method}

\section{Participants}

Participants were 40 undergraduate students at a West Coast university ( $45 \%$ men, $55 \%$ women). They were 22 years old on average ( $S D=2.56$ ); $35 \%$ were Caucasian, 50\% Asian American, 12.5\% Latin American, and 2.5\% Other. Participants were assigned to experimental sessions through volunteer sign-ups; they received course credit for their participation.

\section{Experimental Design and Procedure}

We used an imagery task (e.g., Larsen \& Ketelaar, 1991) that asked participants to imagine working in a group with someone who perceives his status to be either high or low and who actually had either high or low status. To increase the vividness of the image, we asked them to write down the behaviors in which they believe such a person would engage. The experiment involved four conditions in a $2 \times 2$ between-subjects design, with self-perceived status (high vs. low) and peer-perceived status (high vs. low) as the two factors. For example, in the self-enhancement condition (i.e., high self-perception, low peer-perceptions), participants were told the following: 
Imagine you are working in a six-person group (this could be a class project team, a school committee, or a workgroup at your job). Imagine that there is one person in the group, Dave, who overestimates his status. He thinks that everyone respects and admires him more than they actually do, and he thinks he is "in charge" more than he actually is. To put it more concretely, Dave thinks he's among the top two most influential and respected people in the six-person group. In reality, he's among the bottom two. Think for a minute about how a person like Dave would behave. What specific behaviors would he exhibit? Please list a few behaviors you think Dave would exhibit.

Participants in the high-status accurate perceiver condition (i.e., high self-perception, high peer-perception) were given the similar instructions, except they were asked to imagine Adam, who accurately estimates his high status. In the low-status accurate perceiver condition, participants were asked to imagine Barry, who accurately estimates his low status in the group. And in the self-effacement condition, participants were asked to imagine John, who underestimates his status in the group. In all conditions, after participants had written down a list of behaviors, they rated the target individual and the group on a number of dimensions (described below).

\section{Measures}

Social acceptance. Because social acceptance involves the amount an individual is liked and included by others in a group (Baumeister \& Leary, 1995), participants rated the target's likeability and alienation (or lack of inclusion): "His behavior would make group members like him" and "His behavior would make group members avoid him," (reverse scored) on a scale from 1 (disagree strongly) to 7 (agree strongly). The two items were combined to form one measure of social acceptance (alpha reliability coefficient $=.62$ ).

Perceived disruptiveness. Participants rated five items on a scale from 1 (disagree strongly) to 7 (agree strongly): "His behavior would create conflict in the group," "His behavior would make it difficult for the group to work together," "His behavior would harm the group's performance," "His behavior would create personal disagreements in the group," and "His behavior would create work-related disagreements." These five items were combined to form one measure of perceived disruptiveness (alpha reliability coefficient $=.88$ ).

\section{Results and Discussion}

\section{The Effects of Status Self-Perceptions on Social Acceptance}

To examine the effects of status self-enhancement and effacement on social acceptance, we ran a $2 \times 2$

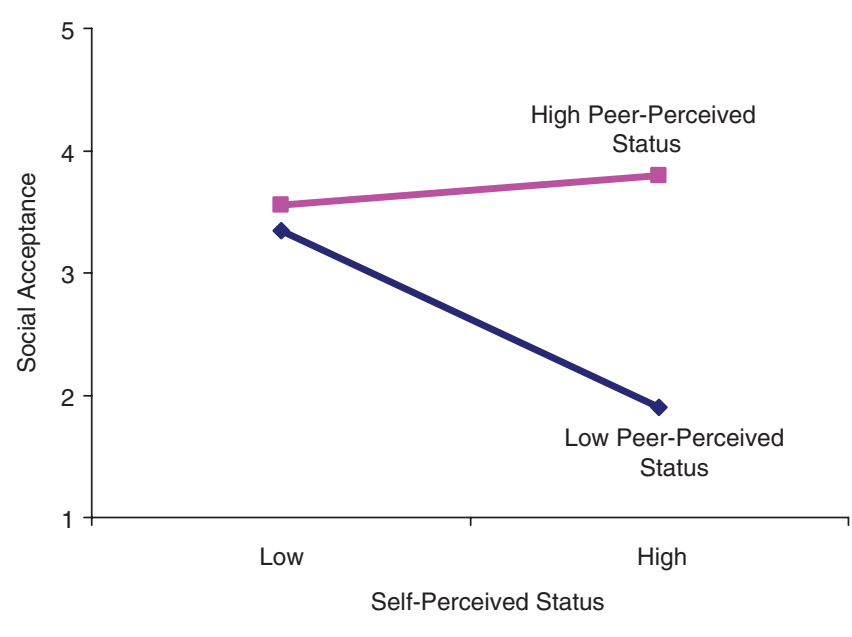

Figure 2 Study 2: Status self-enhancement caused individuals to be less liked and accepted. "Low" and "high" refer to the conditions in which the target individual had a low or a high self-perception of status, respectively.

ANOVA with self-perception (high vs. low) and peerperceptions (high vs. low) as the two factors. As shown in Figure 2, we obtained an interaction such that the effects of self-perceived status on social acceptance depended on the target's actual status, $F(1,39)=5.81$, $p<.05$. Planned comparisons showed that status selfenhancers (i.e., individuals with high self-perceptions of status who actually had lower status) were less accepted $(M=1.90, S D=0.77)$, compared to individuals who had high status and accurately perceived their status $(M=3.80, S D=1.08 ; t[18]=-4.51, p<.01)$, individuals who had low status and accurately perceived their status $(M=3.35, S D=1.25 ; t[18]=-3.12, p<$ $.01)$, and individuals who had high status but perceived that they had low status $(M=3.55, S D=1.28 ; t[18]=$ $-3.49, p<.01)$. There were no other significant differences between any other conditions. Status self-effacers were not liked more than were accurate status perceivers who had either high or low status.

\section{Were Status Self-Enhancers Less Accepted Because They Were Perceived to Be Disruptive?}

Testing whether the effect of status self-enhancement was mediated by perceived disruptiveness involves testing for mediated moderation-that is, whether the interaction we observed between self-perceptions and peer ratings of status was mediated by perceived disruptiveness. We conducted a Sobel test and followed the guidelines for mediated moderation set out by Muller, Judd, and Yzerbyt (2005).

As expected, the effect of self-perceived status on perceived disruptiveness was moderated by peer-rated status, $F(1,39)=5.29, p<.05$. Status self-enhancers 
were perceived as more disruptive to the group $(M=5.26$, $S D=0.81)$, compared to accurate perceivers who had high status $(M=4.00, S D=1.36 ; t[18]=2.52$, $p<.05)$, accurate perceivers who had low status $(M=$ $3.84, S D=0.97 ; t[18]=3.55, p<.01)$, and status selfeffacers $(M=4.24, S D=1.32 ; t[18]=2.08, p=.05)$. There were no other differences between conditions. Also as expected, targets who were perceived as more disruptive were less accepted, $\beta=-.50, t(39)=-3.57$, $p<.01$. Finally, perceived disruptiveness mediated the moderated effect of self-perceived versus peer-perceived status on social acceptance, $t(39)=1.93, p=.05$. This indicates that status self-enhancement lead to lower levels of social acceptance because status self-enhancers were perceived to be disruptive to the group. Note that this was not complete mediation; when controlling for perceived disruptiveness, the interaction between selfperceptions and peer ratings of status in predicting acceptance dropped below significance, $\mathrm{F}(1,39)=2.46$, $p=.13$, but there was still some variance $(M s=2.75)$ explained by the direct effect of the interaction.

\section{Summary}

Using an experimental design, we found that individuals who engaged in status self-enhancement were less accepted than were accurate status perceivers (who had high or low status) and status self-effacers. Moreover, we found no significant difference between status self-effacers and accurate status perceivers in their social acceptance. Although we hesitate to emphasize a null finding, this suggests that there are no additional benefits of underestimating one's status and that the linear results found in Study 1 might have been because of statistical limitations. Finally, we found that the effect of status self-enhancement on acceptance was mediated in part by perceived disruptiveness; this provides at least suggestive evidence that status self-enhancers were liked less in part because they were perceived as socially disruptive.

\section{STUDY 3: THE CONSEQUENCES OF STATUS SELF-ENHANCEMENT IN ORGANIZATIONS}

So far, evidence for the costs of status self-enhancement has stemmed from laboratory groups of undergraduate students. It is possible, therefore, that in more realistic, long-term groups status self-enhancement is beneficial rather than costly. In many contexts outside the laboratory such as organizational settings, self-confidence and assertiveness are highly valued and rewarded (e.g., Rudman, 1998). Inasmuch as status self-enhancement conveys confidence and assertiveness to others, it might relate positively rather than negatively to social acceptance in organizations. In Study 3, we examine status self-enhancement and its social consequences among coworkers in organizations. If we were to obtain similar findings as those in Studies 1 and 2, we would be more assured that our status awareness account generalizes to real-world groups.

Studying status self-enhancement in organizational settings also helps avoid a potential confound inherent in Study 2: demand characteristics. Participants in Study 2 might have guessed that the experiment was testing whether status self-enhancers would be liked less and adjusted their ratings accordingly. In Study 3, as in Study 1 , raters judged the targets' status and acceptance and were unaware of the targets' self-perceived status; it was highly unlikely raters were able to guess the aims of the study.

Along a similar vein, it was important that we examine actual status self-enhancement in Study 3, which involves having overly positive self-perceptions, rather than peer-perceived status self-enhancement, as we did in Study 2, which involves being perceived as having overly positive self-perceptions. Actual status selfenhancement may not have the same negative social costs as perceived status self-enhancement because actual self-enhancement is sometimes hidden under a veneer of charm and likeability (Oltmanns, Friedman, Fiedler, \& Turkheimer, 2004; Paulhus, 1998).

\section{Method}

\section{Participants}

Participants were 54 employees of one of five different organizations: a commercial real estate agency, an advertising agency, a business school, an architectural firm, and a retail bank; $59.3 \%$ of the participants were female; almost all were Caucasian. The average age was $37.24(S D=10.51)$ and the average tenure in their organization was 7.51 years $(S D=8.35)$.

To obtain peer ratings, each participant gave a survey to a coworker in the organization who knew them well (average acquaintance with participant $=5.06$ years, $S D=1.27$ years). The peers completed these surveys confidentially and mailed them directly back to us.

\section{Status Measures}

Participants rated their own status in the organization with two items: "How much status (i.e., respect, prominence) do you have among people in the organization?" and "How much power and influence do you have among people in the organization?" on a scale from 1 (very little) to 7 (very much). These items were combined to form a composite measure of self-perceived status (alpha reliability coefficient $=.85$ ). Peers rated participants' status in the organization with the same 
two items: "How much status (i.e., respect, prominence) does X have among people in the organization?" and "How much power and influence does $\mathrm{X}$ have among people in the organization?" on a scale from 1 (very little) to 7 (very much), where $X$ referred to the participant. These peer ratings were combined to form a composite measure of peer-rated status (alpha reliability coefficient $=.88$ ).

\section{Social Acceptance}

Coworkers also rated participants' social acceptance by rating how likeable $(M=6.17, S D=1.18)$ and alienated or lonely they saw them $(M=2.95, S D=$ 1.86) on a scale from 1 (strongly disagree) to 7 (strongly agree). These items correlated only $-.29(p<.05)$; they were thus kept as separate dependent variables.

\section{Results and Discussion}

\section{The Effects of Status Self-Enhancement}

As expected, individuals who engaged in status selfenhancement were rated as less likeable by their coworkers. We predicted peer-rated likeability with self-rated status, $\beta=-.31, t(53)=-2.54, p<.05$, while controlling for peer-rated status, $\beta=.40, t(53)=4.56, p<.01$; note that because these data were not round robin, we did not control for targets' perceptions of others' status. Furthermore, individuals who status self-enhanced were rated as more lonely and alienated by their coworkers. We predicted peer-rated alienation with self-rated status, $\beta=.29, t(53)=2.08, p<.05$, while controlling for peer-rated status, $\beta=-.26, t(53)=-1.88, p=.06$. Neither of these effects was moderated by gender.

The zero-order correlations were $r(54)=-13$, ns, between self-rated status and peer-rated likeability, and $r(54)=.21, n s$, between self-rated status and peer-rated alienation. These findings suggest that status selfenhancement, not self-perceptions of status, related to lower levels of acceptance and higher levels of alienation.

\section{Self-Perception Accuracy}

Differential accuracy. As expected, self-perceptions of status correlated with peer ratings of status, $r(54)=.33$, $p<.01$. The accuracy correlation is somewhat lower than that found in Study 1, likely because we used only one peer rater in this study (vs. three raters in Study 1), which would tend to reduce the reliability of the peer ratings and constrain the magnitude of the correlation. We found no gender differences in self-peer agreement.

Elevation accuracy. We ran a two-way mixed-within ANOVA with self-perceptions versus peer perceptions as the within-subjects variable and participants' gender as the between-subjects variable. This analysis revealed no main effect for self-perception versus peer perception, $F(1,52)=.39$, $n s$, indicating that there was no selfenhancement effect in perceptions of status. The mean self-perception of status was $4.06, S D=1.52$, and the mean peer rating of status was $4.27, S D=1.67$. There was also no effect for gender nor an interaction between gender and self-perception versus peer perception. This elevation accuracy contrasts with individuals' tendency to self-enhance on other dimensions, such as their abilities (Ehrlinger \& Dunning, 2003; McGraw, Mellers, \& Ritov, 2004; Swann \& Gill, 1991), personality traits (Kwan et al., 2004), or behaviors (Gosling et al., 1998).

\section{Summary}

We found support for both our primary hypotheses in Study 3. In organizational settings, individuals who status self-enhanced were less liked and more alienated. Furthermore, most individuals perceived their status accurately rather than overestimating their status.

\section{GENERAL DISCUSSION}

Across three investigations that together involved a laboratory study of newly formed teams, an experimental design, and a field study of organizations, we found consistent evidence that individuals incurred social costs when they engaged in status self-enhancement. Individuals who formed overinflated perceptions of their status were liked less by others and rated as more lonely and alienated. An experimental design (Study 2) demonstrated the causal priority of status self-enhancement in this relation.

We also found suggestive evidence that status selfenhancers were socially rejected in part because others perceived them as being disruptive to the group-that is, because they were seen as creating conflict in the group, making it difficult for the group to work together, and harming the group's overall performance. This finding supports the assumptions underlying functional theories of status (Berger et al., 1972; Ridgeway \& Berger, 1986; Thibaut \& Kelley, 1959): Individuals must perceive their status accurately for status hierarchies to help coordinate the group's actions, and groups punish individuals for disrupting that function.

We also tested whether status self-enhancement might be adaptive in other ways, providing instrumental (see Krebs \& Denton, 1997) or psychological (see Barkow, 1975) benefits, but we did not find evidence for either hypothesis. Status self-enhancers received less, not more, material compensation from fellow group 
members; group members seemed to punish status selfenhancers financially through lower levels of compensation. And individuals who engaged in status self-enhancement did not have higher levels of self-esteem but instead exhibited higher levels of narcissism.

By comparison, groups did not punish individuals who engaged in self-enhancement when perceiving their acceptance. In Study 1, individuals who overestimated their acceptance were not assigned a lower number of lottery tickets by their peers. This finding is important for two reasons. First, it highlights the uniqueness of status self-enhancement. Self-enhancement in domains other than status, such as social acceptance, should not disrupt group processes and performance in the same way as status self-enhancement. Therefore, there should be less reason for groups to punish other forms of selfenhancement. Second, it helps explain why individuals engaged in acceptance self-enhancement at the same time they accurately perceived their status-namely, they were free to do so.

Individuals generally did not engage in status selfenhancement but instead perceived their status comparatively accurately. In particular, in Study 1, where we used more than one peer rater, the differential accuracy correlation was .67. This accuracy is especially high relative to the differential accuracy we observed in selfperceptions of acceptance, $r=.10$.

\section{Theoretical Implications}

This research tested opposing hypotheses regarding self-perceptions of status that were derived from two different theoretical perspectives: functional theories of status (Ridgeway \& Berger, 1986; Thibaut \& Kelley, 1959 ) and positive illusion theories (Taylor \& Brown, 1988). In finding that status self-enhancement incurred a host of costs, it extended prior research (Anderson et al., 2006) and provided further evidence in support of the functionalist theories of status.

As some studies have shown, there can be benefits to forming overly positive self-perceptions, including higher levels of self-confidence and increased task motivation and performance (Diener \& Dweck, 1978; Kwan et al., 2004; Taylor \& Brown, 1988; Taylor et al., 2003). However, this research presents an important boundary condition for the hypotheses posed by positive illusion theories. In so doing, this research extends a line of studies showing that there can be costs associated with various forms of self-enhancement. For example, overly positive self-perceptions have been related to achieving less optimal outcomes in negotiations (Neale \& Bazerman, 1985), disengagement from academic pursuits (Robins \& Beer, 2001), being seen as hostile and cold by others (Colvin, Block, \& Funder,
1995; Paulhus, 1998), and experiencing less enjoyment following a success (McGraw et al., 2004).

\section{Future Directions}

There are a number of aspects of these findings that call for further study. We have theorized that the fear of social rejection and alienation keeps individuals from engaging in status self-enhancement. It is also possible, however, that individuals are intrinsically motivated to perceive their status accurately. According to sociometer theory (M. R. Leary, Cottrell, \& Phillips, 2001), status has been associated with increased reproductive success in our ancestral environment and, thus, individuals have evolved a motivation and ability to monitor their social standing accurately. Future research should further explore why individuals keep their status selfperceptions in check.

Second, although status self-enhancement seems to incur costs, there might be some conditions in which it is beneficial. For example, in the beginning of a group's development and before individuals know each other, status self-enhancers might be given the status they claim; it might be that status self-enhancement is costly only after a hierarchy develops. It is also possible that status self-enhancers win others' respect and esteem when interacting with people outside their group. People outside their group may not react negatively because they are not aware of the person's actual place within the group. Finally, even in the contexts we studied, there may have been benefits to status self-enhancement we did not observe. For example, in Study 3, status self-enhancers might have enjoyed benefits such as higher job performance or an enhanced reputation for productivity.

Similarly, acceptance self-enhancement might have negative social consequences we did not observe. For example, if individuals overestimate their closeness with others, they might overestimate the likelihood of receiving support when needed (e.g., in times of financial or emotional hardship). Furthermore, overestimating one's closeness to others might lead individuals to ask others for favors under the assumption that others will gladly comply. As recent research suggests, this can elicit enmity because others tend to comply out of obligation and then resent the individual (Flynn \& Bohms, 2005).

\section{Conclusion}

Functionalist theories of status argue that status hierarchies provide many benefits for face-to-face groups, including a clear order of influence among group members. However, for status hierarchies to provide these benefits, individual group members must be willing to perceive their status accurately-otherwise the 
system breaks down. Too many group members would fight for control over group processes and decisions. On the other hand, for individuals to refrain from engaging status self-enhancement, they would forego the opportunity to boost their self-esteem. On a broader level, then, these studies addressed a tension between a group's need to maintain order and individuals' need to maintain a positive sense of self. Consistent with prior research (Anderson et al., 2006), we found evidence suggesting that the group's needs dominate; individual group members do indeed perceive their status accurately and do not status self-enhance.

\section{NOTES}

1. Social acceptance involves how well individuals get along with others, how many friends they have, and how well-liked they are by their peers, whereas status involves how well individuals get ahead or how much they have risen above others in the group's hierarchy (Baumeister \& Leary, 1995; Hogan, 1983). Thus, although social acceptance and status seem highly similar, in several theories they are conceptually orthogonal dimensions (Hogan, 1983; Homans, 1951; Moskowitz, 1994; Wiggins, 1979). Individuals who are well liked in a group are not necessarily admired and influential, and influential individuals are sometimes disliked.

2. Given the link between narcissism and status self-enhancement, we wanted to rule out the possibility that narcissism might have acted as a third variable, driving the relation between status self-enhancement and our social and instrumental outcomes. Even after controlling for narcissism, the effect of status self-enhancement on social acceptance $(\beta=-.22, p=.05)$ and lottery tickets $(\beta=-.26, p<.05)$ remained significant.

3. Both status and acceptance differ from other dimensions of social perception in an important way. For many other dimensions, when individuals' self-perceptions diverge from other people's perceptions, it is unclear which perceiver has a stronger claim on truth (Hofstee, 1994; Robins \& John, 1997). That is not the case for status or acceptance because other people's perceptions are the very definition of both dimensions. When individuals disagree with others about their status or their acceptance, their self-perceptions are inaccurate in the deepest sense of the term.

4. There were 8 all-female groups, 17 groups with one male, 11 groups with two males, and 4 groups with three males. We excluded 1 group from this analysis because it was missing information on members' gender.

\section{REFERENCES}

Allison, S. T., Messick, D. M., \& Goethals, G. R. (1989). On being better but not smarter than others: The Muhammad Ali effect. Social Cognition, 7, 275-295.

Anderson, C., \& Berdahl, J. L. (2002). The experience of power: Examining the effects of power on approach and inhibition tendencies. Journal of Personality and Social Psychology, 83, 1362-1377.

Anderson, C., Srivastava, S., Beer, J., Spataro, S. E., \& Chatman, J. A. (2006). Knowing your place: Self-perceptions of status in social groups. Journal of Personality and Social Psychology, 91, 1094-1110.

Bakan, D. (1966). The duality of human existence: An essay on psychology and religion. Chicago: Rand McNally.

Bales, R. F., Strodtbeck, F. L., Mills, T. M., \& Roseborough, M. E. (1951). Channels of communication in small groups. American Sociological Review, 16, 461-468.
Barkow, J. H. (1975). Prestige and culture: A biosocial interpretation. Current Anthropology, 16, 553-562.

Baumeister, R. F., \& Leary, M. R. (1995). The need to belong: Desire for interpersonal attachments as a fundamental human motivation. Psychological Bulletin, 117, 497-529.

Berger, J., Cohen, B. P., \& Zelditch, M. (1972). Status characteristics and social interaction. American Sociological Review, 37, 241-255.

Bernstein, I. S. (1981). Dominance: The baby and the bathwater. Behavioral and Brain Sciences, 4, 419-457.

Blau, P. M. (1964). Exchange and power in social life. New York: Wiley.

Blau, P. M., \& Scott, W. R. (1962). Formal organizations: A comparative approach. San Francisco: Chandler.

Bugental, D. B., \& Lewis, J. C. (1999). The paradoxical misuse of power by those who see themselves as powerless: How does it happen? Journal of Social Issues, 55, 51-64.

Colvin, C. R., Block, J., \& Funder, D. C. (1995). Overly positive self-evaluations and personality: Negative implications for mental health. Journal of Personality and Social Psychology, 68, 1152-1162.

Cronbach, L. J. (1955). Processes affecting scores on "understanding others" and "assumed similarity." Psychological Bulletin, 52, 177-193.

de Waal, F. (1982). Chimpanzee politics: Power and sex among apes. New York: Harper \& Row.

Diener, C. I., \& Dweck, C. S. (1978). An analysis of learned helplessness: Continuous changes in performance, strategy, and achievement cognitions following failure. Journal of Personality and Social Psychology, 36, 451-462.

Edwards, J. R. (1994). The study of congruence in organizational behavior research: Critique and a proposed alternative. Organizational Behavior and Human Decision Processes, 58, 51100.

Ehrlinger, J., \& Dunning, D. (2003). How chronic self-views influence (and potentially mislead) estimates of performance. Journal of Personality and Social Psychology, 84, 5-17.

Eibl-Eibesfeldt, I. (1989). Human ethology. Hawthorne, NY: Aldine De Gruyter.

Flynn, F. J., \& Bohms, V. (2005). Just ask: How people underestimate the likelihood of compliance in favor exchange. Manuscript submitted for publication.

Frank, R. H. (1985). Choosing the right pond: Human behavior and the quest for status. New York: Oxford University Press.

Gosling, S. D., John, O. P., Craik, K. H., \& Robins, R. W. (1998). Do people know how they behave? Self-reported act frequencies compared with on-line codings by observers. Journal of Personality and Social Psychology, 74, 1337-1349.

Hofstee, W. K. B. (1994). Who should own the definition of personality? European Journal of Personality, 8, 149-162.

Hogan, R. (1983). A socioanalytic theory of personality. In M. Page (Ed.), Nebraska symposium on motivation, 1982: PersonalityCurrent theory and research (pp. 55-89). Lincoln: University of Nebraska Press.

Hogan, R. (1996). A socioanalytic perspective on the five-factor model. In J. S. Wiggins (Ed.), The five-factor model of personality: Theoretical perspectives (pp. 163-179). New York: Guilford.

Homans, G. C. (1951). The human group. London: Routledge \& Kegan Paul.

Horowitz, L. M., Wilson, K. R., Turan, B., Zolotsev, P., Constantino, M. J., \& Henderson, L. (2006). How interpersonal motives clarify the meaning of interpersonal behavior: A revised circumplex model. Personality and Social Psychology Review, 10, 67-86.

John, O. P., \& Robins, R. W. (1994). Accuracy and bias in self-perception: Individual differences in self-enhancement and the role of narcissism. Journal of Personality and Social Psychology, 66, 206-219.

Kenny, D. A. (1994). Interpersonal perception. New York: Guilford.

Kenny, D. A. (1995). SOREMO V.2: A FORTRAN program for the analysis of round-robin data structures. Unpublished manuscript, University of Connecticut.

Kenny, D. A., \& La Voie, L. (1984). The social relations model. In L. Berkowitz (Ed.), Advances in experimental social psychology (Vol. 18, pp. 142-182). Orlando, FL: Academic Press. 
Krebs, D. L., \& Denton, K. (1997). Social illusions and self-deception: The evolution of biases in person perception. In J. A. Simpson \& D. T. Kenrick (Eds.), Evolutionary social psychology (pp. 21-48). Mahwah, NJ: Lawrence Erlbaum.

Kwan, V. S., John, O. P., Kenny, D. A., Bond, M. H., \& Robins, R. W. (2004). Reconceptualizing individual differences in self-enhancement bias: An interpersonal approach. Psychological Review, 111, 94-110.

Larsen, R. J., \& Ketelaar, T. (1991). Personality and susceptibility to positive and negative emotional states. Journal of Personality and Social Psychology, 61, 132-140.

Leary, T. (1957). Interpersonal diagnosis of personality. New York: Ronald.

Leary, M. R., Cottrell, C. A., \& Phillips, M. (2001). Deconfounding the effects of dominance and social acceptance on self-esteem. Journal of Personality and Social Psychology, 81, 898-909.

Maslow, A. H. (1968). Toward a psychology of being. New York: Van Nostrand.

McClelland, G. H., \& Judd, C. M. (1993). Statistical difficulties of detecting interactions and moderator effects. Psychological Bulletin, 114, 376-390.

McGraw, A. P., Mellers, B. A., \& Ritov, I. (2004). The affective costs of overconfidence, Journal of Behavioral Decision Making, 17, 281-295.

Morf, C. C., \& Rhodewalt, F. (2001). Unraveling the paradoxes of narcissism: A dynamic self-regulatory processing model. Psychological Inquiry, 12, 177-196.

Moskowitz, D. S. (1994). Cross-situational generality and the interpersonal circumplex. Journal of Personality and Social Psychology, 66, 921-933.

Muller, D., Judd, C. M., \& Yzerbyt, V. Y. (2005). When moderation is mediated and mediation is moderated. Journal of Personality and Social Psychology, 89, 852-863.

Neale, M. A., \& Bazerman, M. H. (1985). The effects of framing and negotiator overconfidence on bargaining behaviors and outcomes. Academy of Management Journal, 28, 34-49.

Oltmanns, T. F., Friedman, J. N. W., Fiedler, E. R., \& Turkheimer, E. (2004). Perceptions of people with personality disorders based on thin slices of behavior. Journal of Research in Personality, 38, 216-229

Paulhus, D. L. (1998). Interpersonal and intrapsychic adapativeness of trait self-enhancement: A mixed blessing? Journal of Personality and Social Psychology, 74, 1197-1208.

Paulhus, D. L., \& John, O. P. (1998). Egoistic and moralistic biases in self-perception: The interplay of self-deceptive styles with basic traits and motives. Journal of Personality, 66, 1025-1060.

Raghunathan, T. E., Rosenthal, R., \& Rubin, D. B. (1996). Comparing correlated but nonoverlapping correlations. Psychological Methods, $1,178-183$.
Raskin, R., \& Terry, H. (1988). A principal-components analysis of the Narcissistic Personality Inventory and further evidence of its construct validity. Journal of Personality and Social Psychology, 54, 890-902.

Ridgeway, C. L., \& Berger, J. (1986). Expectations, legitimation, and dominance behavior in task groups. American Sociological Review, 51, 603-617.

Robins, R. W., \& Beer, J. S. (2001). Positive illusions about the self: Short-term benefits and long-term costs. Journal of Personality and Social Psychology, 80, 340-352.

Robins, R. W., \& John, O. P. (1997). Effects of visual perspective and narcissism on self-perception: Is seeing believing? Psychological Science, 8, 37-42.

Rosenberg, M. (1965). Society and the adolescent self-image. Princeton, NJ: Princeton University Press.

Rudman, L. A. (1998). Self-promotion as a risk factor for women: The costs and benefits of counterstereotypical impression management. Journal of Personality and Social Psychology, 74, 629-645.

Savitsky, K., Van Boven, L., Epley, N., \& Wight, W. M. (2005). The unpacking effect in allocations of responsibility for group tasks. Journal of Experimental Social Psychology, 41, 447-457.

Swann, W. B., \& Gill, M. J. (1991). Confidence and accuracy in person perception: Do we know what we think we know about our relationship partners? Journal of Personality and Social Psychology, 73, 747-757.

Taylor, S. E., \& Brown, J. D. (1988). Illusion and well-being: A social psychological perspective on mental health. Psychological Bulletin, 103, 193-210.

Taylor, S. E., Lerner, J. S., Sherman, D. K., Sage, R. M., \& McDowell, N. K. (2003). Portrait of the self-enhancer: Well adjusted and well liked or maladjusted and friendless? Journal of Personality and Social Psychology, 84, 165-176.

Thibaut, J. W., \& Kelley, H. H. (1959). The social psychology of groups. New York: Wiley.

Van Lange, P. A. M., \& Sedikides, C. (1998). Being more honest but not necessarily more intelligent than others: Generality and explanations for the Muhammad Ali effect. European Journal of Social Psychology, 28, 675-680.

Vazire, S., \& Funder, D. C. (2006). Impulsivity and the self-defeating behavior of narcissists. Personality and Social Psychology Review, 10, 154-165.

Wiggins, J. S. (1979). A psychological taxonomy of trait-descriptive terms: The interpersonal domain. Journal of Personality and Social Psychology, 37, 395-412.

Received November 15, 2006

Revision accepted June 3, 2007 